Proceedings of the Institution of
Civil Engineers
Engineering Sustainability 161
September 2008 Issue ES3
Pages 161-172
doi: $10.1680 /$ ensu.2008.161.3.161
Paper 800012
Received 20/10/2005
Accepted 16/06/2008
Keywords:
buildings, structure \& design/
management

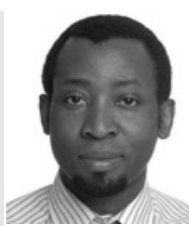

Israel Adetunji Centre for Innovative Construction Engineering Loughborough University, UK

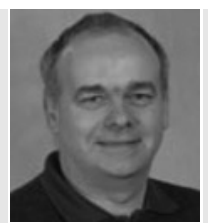

Andrew D. F. Price Centre for Innovative Construction Engineering Loughborough University UK

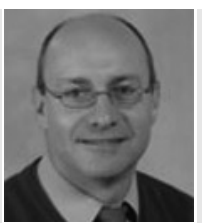

Paul Fleming Centre for Innovative Construction Engineering Loughborough University UK

\title{
Achieving sustainability in the construction supply chain
}

\section{Adetunji MSc, EngD, A. D. F. Price PhD, CEng, FICE, FCIOB and P. Fleming PhD, GradICE, MIHT}

Sustainable construction and supply chain management (SCM) have, in recent years, become two of the most important performance-related issues within the construction industry. To achieve corporate sustainability within any organisation, it is essential that sustainability issues are addressed throughout the organisation's whole supply chain, a process referred to as sustainable supply chain management (SSCM). The implementation of SCM and sustainability is, however, an extremely complex undertaking. Through an extensive literature review and detailed interviews, this research has identified the conditions and strategies for achieving SSCM within construction organisations. The research also investigated the meaning, barriers and enablers, issues, tools and techniques for achieving successful SCM and SSCM. The study was based on the perspectives of senior managers of exemplar organisations with a proven track record in sustainability and SCM. It has been possible to identify best practice from which other organisations can learn, thus supporting the industry in the move towards more sustainable construction practices.

\section{INTRODUCTION}

Increased environmental, social and economic impacts of the construction industry and its products have fuelled the demand for sustainable construction. ${ }^{1}$ During the 1990 s and in response to perceived recurrent problems of poor quality of work, budget constraints in the public sectors, ${ }^{2-4}$ under-performance, low productivity, low profit margins, adversarial relationships and the fragmented nature of the construction industry, various UK government reports and initiatives concurrently suggested that the industry would benefit from adopting better sustainable construction and supply chain management (SCM). ${ }^{5,6}$ SCM has thus become an important aspect of construction performance in the UK. Recent developments include

(a) a proliferation of various forms of SCM and procurement in the construction industry

(b) traditional performance measures (time, quality and cost) being expanded to include additional factors such as environmental and social measures ${ }^{7}$

(c) the importance of suppliers' sustainability performance becoming one of the key aspects of tender selection criteria ${ }^{8}$ (d) many large construction companies developing a variety of tools, policies and strategies that measure and demonstrate their performance. ${ }^{9}$

There is growing awareness that sustainability cannot be achieved by organisations' actions in isolation. They need to work in partnership with other members of the supply chain to develop products and services based on environmental integrity, social equity and commercial viability. ${ }^{10}$ Accordingly, many frameworks for implementing sustainability at the business strategic level (e.g. Sigma ${ }^{11}$ and The Natural Step ${ }^{12}$ ) advocate the integration of sustainability within SCM. This perception is increasingly being shared among early adopters of sustainable concept (e.g. The Body Shop, BCtQ and Pilkington) and sustainable construction (e.g. Balfour Beatty, Carillion and Amec). The concepts of sustainability and SCM are, however, extremely complex and problems exist when theory is being translated into practice. ${ }^{13}$ To achieve sustainable construction and SCM, there is consensus that the government must take the lead through its spending power and legislation.

Sustainable supply chain management (SSCM) has been defined in the context of this research as: identification of problematic economic, social and environmental issues throughout the supply chain; assessment of their potential impact and risks; and development of measures to enhance impact and mitigate risk. ${ }^{13}$ There is, however, still on-going debate into how best to implement SCM and sustainability as separate concepts, let alone through an integrated approach to SSCM. The merging of these two concepts does not help to improve understanding or make practical application easier. In recent years, there has been considerable research into the separate issues of sustainability and SCM; however, the concept of SSCM is still in its embryonic stage. Carter et al. ${ }^{14}$ recommended in-depth research into SSCM tools and strategies, aimed at developing a better understanding of benefits and barriers of SSCM at company level. A review of recent literature indicates that SSCM has become a major focus in many industries with the construction industry lagging behind. There are, however, some proactive construction organisations (albeit large organisations) that are addressing aspects of SSCM, but little research to document this trend.

The aim of the current study was to establish the conditions and strategies for achieving SSCM in the construction industry. To achieve this, the research investigated SCM and SSCM definitions, barriers, enablers, issues, tools and techniques. 
The UK construction industry is, however, extremely complex and embraces civil engineering, building engineering, manufacture, waste management, maintenance of roads and the process sector. ${ }^{15}$ Even though the modes of execution are comparable, the scale, complexity and intricacy within the multitude of supply chains for construction products and services differ considerably. ${ }^{16}$ Furthermore, the implementation of sustainability and SCM is still confined within the remit of a few proactive large construction companies (notably those with government as major clients). The complexity of the UK industry, the novelty of SSCM and the need for an in-depth study of exemplar organisations justify a focus on a specific sector. An example is road maintenance, where governmental bodies such as local authorities and the Highways Agency are the main clients with clearly identifiable supply chains.

\section{METHODOLOGY}

A case-study-based research methodology was adopted and comprised a combination of data derived from $(a)$ an extensive literature review of academic journals, company archives and information (see section 3) and (b) in-depth semi-structured interviews (see section 4) with three clients, three suppliers, three contractors and two subcontractors within the road maintenance sector. There are two main reasons for focus on the road maintenance sector: the characteristics of the road maintenance sector and the sustainability issues addressed within the sector are similar to those of the construction industry as a whole; and there is evidence of well-established SCM techniques (long-term strategic partnering) within the sector.

The research explored the perceptions of the parties involved at the key interfaces of SCM. A case study approach was used for the investigation, mainly due to the need to retain the holistic and meaningful characteristics of real-life events. ${ }^{17}$ As can be seen from Table 1, a total of 19 staff (from 11 companies) involved in developing and implementing sustainable construction and SCM strategies were interviewed. The sample comprised respondents who perform different functions in their organisations at different levels of the supply chain. The companies studied were chosen as exemplars of sustainable construction implementation both within their organisations and throughout their supply chain. Good practice was thus identified from which other organisations could learn, improve and encourage the industry as a whole to implement SSCM. Access was provided by clients and contractors to their key suppliers and subcontractors; however, only five of these agreed to be interviewed.

This research is based on the opinion of senior managers, from exemplar organisations within the highways maintenance sector, on issues relating to SCM and SSCM, including procurement, environment, health and safety and marketing. The research does not purport to be an exhaustive analysis of the entire road maintenance sector, but provides indicative trends within the sector. The findings are not, however, restricted to that sector. Most of the issues raised are generic to the whole construction industry and most of the interviewed suppliers and subcontractors tended to work across the industry and not just with the main clients and contractors involved in this sector.

\section{LITERATURE REVIEW}

Based on the premise that successful SSCM relies on wellestablished SCM processes, this section reviews literature regarding SCM definitions, barriers, enablers and conditions for success as well as related sustainability issues, tools and techniques and conditions for successful SSCM.

\section{I. Sustainable construction}

Since the Brundtland Report ${ }^{18}$ in 1987, there has been increased recognition of construction's important role within sustainable development. Adetunji et al. ${ }^{9}$ surveyed the top 45 construction contractors in a review of construction's engagement with sustainability. The research also identified a range of sustainability issues that need to considered and concluded that from an economic perspective, greater emphasis needs to be given to whole-life costs and from an environment perspective, there is a need to reduce the consumption of energy, carbon, waste and materials. However, the industry has yet to understand fully how to deal with many of the emerging social issues such as health, well-being and equity. Although many of the impacts can be dealt with at an organisational level, greater benefits can be achieved if responsibility is taken through the

\begin{tabular}{|c|c|c|c|c|c|c|c|c|}
\hline \multirow[b]{2}{*}{ Company } & \multirow[b]{2}{*}{$\begin{array}{l}\text { Business } \\
\text { type }\end{array}$} & \multirow[b]{2}{*}{$\begin{array}{c}\text { No. of } \\
\text { employees }\end{array}$} & \multicolumn{6}{|c|}{ Position of interviewee } \\
\hline & & & $\begin{array}{l}\text { Environmental } \\
\text { manager }\end{array}$ & $\begin{array}{l}\text { Health and } \\
\text { safety } \\
\text { environmental } \\
\text { manager }\end{array}$ & Director & $\begin{array}{l}\text { Contract } \\
\text { manager }\end{array}$ & $\begin{array}{l}\text { Procurement } \\
\text { manager }\end{array}$ & $\begin{array}{c}\text { Marketing } \\
\text { manager }\end{array}$ \\
\hline$A$ & Client & $>1000$ & $x$ & - & - & - & - & - \\
\hline B & Supplier & $>12000$ & $x$ & - & - & - & - & - \\
\hline C & Supplier & $>1000$ & - & $x$ & - & - & - & - \\
\hline $\mathrm{D}$ & Subcontractor & $>200$ & - & - & $x$ & - & - & - \\
\hline$E$ & Client & $>1000$ & $x$ & - & - & $x$ & - & - \\
\hline $\mathrm{F}$ & Client & $>1000$ & - & - & - & $x$ & $x$ & - \\
\hline G & Contractor & $>2500$ & $x$ & - & - & & $x$ & - \\
\hline $\mathrm{H}$ & Contractor & $>1800$ & $x$ & - & - & $x$ & & - \\
\hline I & Supplier & $>4000$ & $x$ & - & - & - & - & $x$ \\
\hline J & Subcontractor & $>500$ & - & $x$ & - & $x$ & - & - \\
\hline K & Contractor & $>300$ & $x$ & - & - & $x$ & $x$ & - \\
\hline
\end{tabular}


supply chain: end-users can make energy savings during the operating stage, contractors can improve safety and reduce waste, architects and engineers can produce more sustainable design, and suppliers can responsibly source materials.

\subsection{Background to SCM issues and terminology}

Increasing global competition, cost pressure and market uncertainty ${ }^{19}$ have contributed to the pursuit of SCM based on the premise that potential exists to improve customer service, reduce costs and achieve sustainable competitive advantage through upstream and downstream collaboration throughout the value chain. ${ }^{20}$ The key issues addressed ${ }^{21-24}$ within SCM have been collated and are depicted in Fig. 1, which illustrates how many of the issues are interrelated and impact upon one another. Those having the greater dependency are shown closer together.

SCM-related literature contains many definitions and there is neither a universally adopted definition nor certainty on its practical application. ${ }^{25}$ The diversity and complexity of business philosophy embodied in the concept is reflected in the plethora of SCM definitions and confusion surrounding its practical application. In an attempt to clarify debate, several authors ${ }^{26,27}$ have reviewed various definitions for SCM. ${ }^{26-29}$ Research suggests that these variations in definitions and terminologies are mainly based on different standpoints from which it is approached. ${ }^{14,25}$ Fig. 2 illustrates the perspectives of SCM from the public sector and construction and manufacturing industries. The main reason for the different perspectives between construction and manufacturing may lie in the differing emphasis on product or process between the two industries.

\subsection{The dilemma of achieving SCM in the construction industry}

The introduction of construction SCM advocates changes in culture and behaviour that have historically tended to be adversarial, short term and opportunistic. Major studies in the construction industry ${ }^{5,6}$ have suggested that the industry (plagued by a fluctuating demand cycle, uncertain production condition, fragmentised production process and adversarial relationships) can potentially benefit from SCM. ${ }^{30,31}$ Over recent years, there has been a proliferation of SCM research and practice resulting in the implantation of several techniques to varying degrees of success. While SCM can deliver many benefits, ${ }^{32-34}$ it has proved very difficult to implement ${ }^{35}$ and uptake throughout the industry has been conspicuously low. ${ }^{36}$ Recent studies have demonstrated that only a few UK major construction clients and contractors have successfully implemented SCM as an integrated part of their business strategy for procuring projects. ${ }^{37}$

According to Gattorna et al., ${ }^{38}$ the two main weaknesses of SCM are: $(a)$ the difficulty in creating and maintaining a shared vision and strategy; and $(b)$ achieving and maintaining significant behavioural change both internally and externally. Other research has indicated there is little evidence of trust and commitment is virtually non-existent in many collaborative activities. ${ }^{39}$ During periods of significant culture change, organisations and individuals often fear a loss of power and find it difficult to adapt to the new ethos of openness and cost transparency. ${ }^{40}$ Suppliers also often fear that open-book approaches are not really used to gain mutual benefits but rather as a means of reducing already thin profit margins. They often initially view the relationship as more of a win-lose situation rather than the win-win situation purported by most SCM literature. A number of studies have also shown that the costs associated with such improvement activities are biased towards suppliers while the benefits are skewed towards the customer. ${ }^{41,42}$ The achievement of both internal and external alignment is rarely attributable to: a traditional reliance on price as a barometer for success, historical fragmentation of delivery systems and adversarial relationships; ${ }^{30}$ the temporary and one-off nature of most construction projects; ${ }^{43}$ and the belief that trading partners are interchangeable. These dilemmas justify the need to investigate further the main schools of thought relating to successful implementation of SCM.

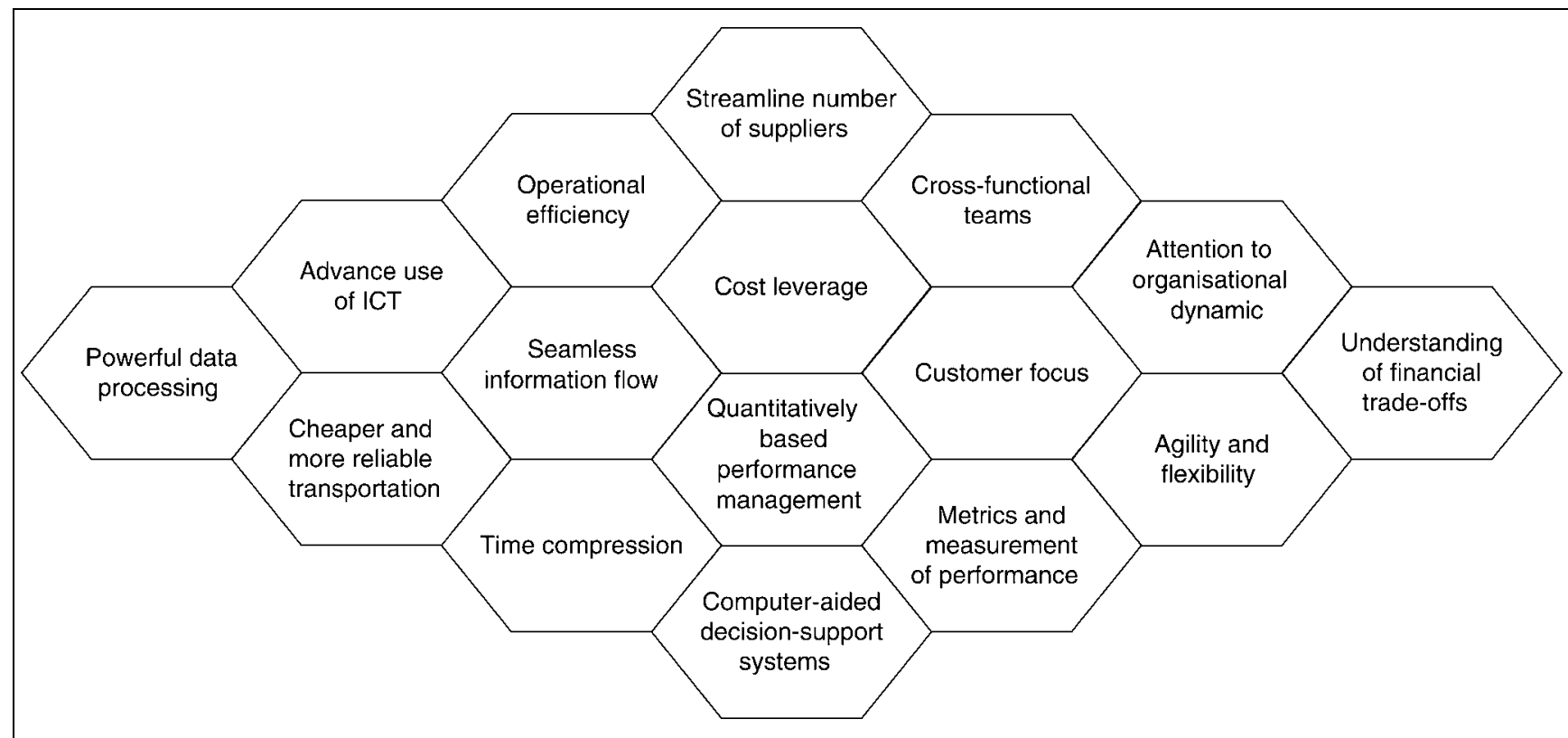

Fig. I. Key SCM issues 


\section{Construction industry's perspective}

Cooperation between main contractor, subcontractors and suppliers and development of these relationships within the supply chain system towards arrangements of lean supply chain partnerships.



Manufacturing industry's perspective Integrated management of materials, information and financial flows from raw material extraction to end-user.
SCM definitions from different perspectives

\section{Public sector's perspective}

'Procurement management' is the preferred term, defined as the management of an organisation's relationship with its direct suppliers (vendors, contractors) and its customers (various departments and agencies).



Fig. 2. SCM definitions from three perspectives

\subsection{Successful SCM in the construction industry: two opposing schools of thought}

The debate on how SCM can be achieved in the construction industry is far from over but it is an area where rhetoric appears to be moving ahead of reality. ${ }^{35,44}$ The literature relating to the conditions for successful SCM in the construction industry can be divided into two main schools of thought as depicted in Fig. 3 and explained below. ${ }^{13,14}$

\subsubsection{School of thought A: operational efficiency and} effectiveness by way of collaboration based on equitable relationships. Most construction literature falls into school of thought $\mathrm{A}$, where the general tenet is that integration and cooperation is the solution to fragmentation, ${ }^{31}$ adversarial culture and low profit margins. ${ }^{5,6}$ A number of factors such as trust, ${ }^{45}$ commitment ${ }^{46}$ and win-win scenarios have been identified as crucial. Trust in this sense means that parties act towards mutual benefits, while commitment is based on the belief that the trading partners are willing to devote energy to sustaining the relationship. A win-win scenario for all parties can be used to safeguard against the tendency simply to act as opportunistic and encourages the various parties to work hard towards a common goal. This approach takes a remarkably benign view of developing and maintaining inter-organisation relationships, ${ }^{25}$ which are often not easy to achieve. While this approach may be appropriate for certain players under certain circumstances, they are unlikely to be appropriate for all players in all circumstances due to the nature and complexity of the construction process. ${ }^{15}$

3.4.2. School of thought B: strategic efficiency and effectiveness by way of collaboration based on power relations. School of thought $\mathrm{B}$ argues that there is a flaw in the assumption that successful SCM, based on trust and equitable relationships, is achievable in all situations ${ }^{47}$ and amenable to all construction processes. It suggests that successful SCM is achieved through collaboration based on a power regime. This occurs when a dominant player is strategically placed and creates a structural hierarchy of relatively dependent suppliers who pose no threat to the flow of value appropriation and are forced to pass value to the dominant player. ${ }^{48,49}$ High purchasing power, regularity and predictability of workload and extensive

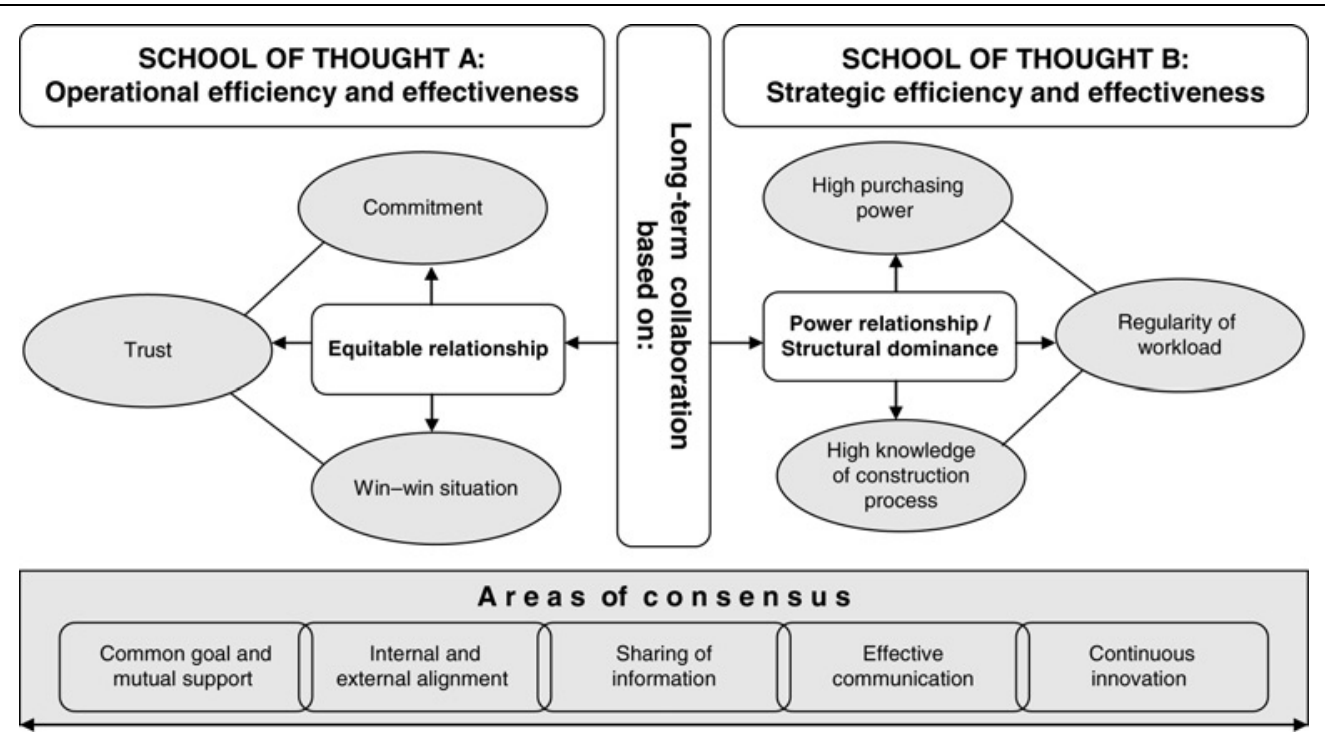

Fig. 3. The two schools of thought for achieving SCM 
knowledge of the construction process are all seen as significant intervening factors, which determine whether or not proactive SCM approaches can be implemented. ${ }^{13}$ These factors provide buyers (clients) with power and the ability to work in a proactive and collaborative manner with trading parties, to achieve its procurement best-value objectives.

\subsubsection{Areas of consensus between the two schools of} thought. Both schools of thought, however, concur on some issues ${ }^{50}$ such as: internal and external alignment through coordinated teams and cross-functional integration to ensure flexible, adaptive and open organisations; appropriate exchange of information and knowledge transfer leading to innovation; effective communication in terms of frequency and quality of information; ${ }^{51}$ willingness to share information to improve overall performance ${ }^{25}$ commitment to common goal and mutual support; ${ }^{52}$ and continuous innovative effort. This review raised an additional research question concerning the interplay of the mode of cooperation (equity and/or power relationship) in the context of successful SSCM.

\subsection{Sustainability and SCM concepts}

Increasing global awareness, driven by the 'global agenda for change, ${ }^{18}$ capacity building, and a proliferation of legislation have put considerable pressure on industries worldwide. Grounded on a well-articulated business case, more companies are proactively implementing sustainability objectives through their business processes. Greater awareness of the need to involve the supply chain as part of a company's wider corporate sustainability agenda is, however, required. ${ }^{10}$ Many studies have documented the environmental, social and economic performance of the construction industry and advocated significant change; ${ }^{1,9}$ however, most of the research into SSCM relates to other industries rather than construction. Constructionrelated research has tended to focus on specific operational and tactical aspects of SCM as sustainable issues ${ }^{53}$ such as: client-contractor relationships; ${ }^{43}$ main contractor and subcontractor/supplier interfaces $;{ }^{29,54}$ environmental performance $;^{55}$ and sustainable construction. In order to aid the construction industry's transition to SSCM, the review of extensive literature discussed so far has facilitated the development of the model in Fig. 4. This illustrates the development of SCM and transition to SSCM.

\subsection{Interview questions emerging from the literature review}

This section summarises key issues that emerged during the review of literature and the resulting interview questions that were subsequently explored within the case study organisations.

Q1: How is the concept of sustainability and supply chain management understood within the case study organisations?

\subsubsection{Functions/departments involved in implementing} SSCM. Successful SCM demands effective and close alignment of various functional units such as purchasing, logistics, marketing and manufacturing as well as suppliers and transportation providers. ${ }^{56-58}$ SSCM widens the scope to include other departments and functions such as environmental, health and safety, contract management, training and development, research and development and human resources. ${ }^{14}$

Q2: To what extent are these functions/departments involved in integrating sustainability issues within the case study organisations?

3.6.2. Sustainability issues for SCM. Within the construction industry, there is a wealth of information on the generic sustainability issues relevant to the construction industry. ${ }^{1,59-61}$ The principal issues associated with the key sustainable construction themes of the UK Government's sustainable development objectives have been mapped out and collated in Table 2 .

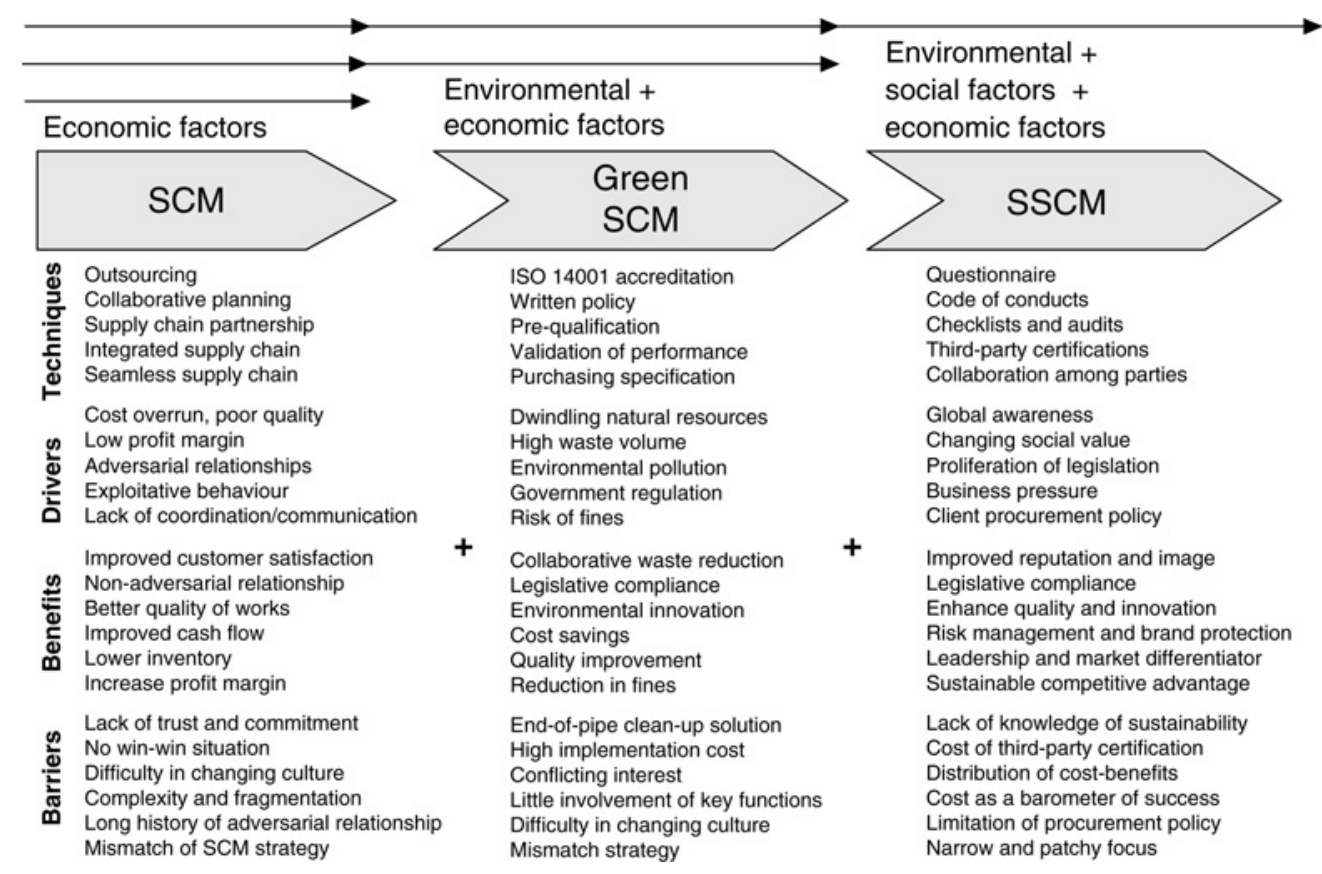

Fig. 4. Development of SCM and transition into SSCM 


Key theme
Economic sustainability
I.0 Maintenance of high and stable levels of local
economic growth and employment

I.I Improved project delivery

I.2 Increased profitability and productivity

1.3 Monitoring and reporting performance

Environmental sustainability

2.0 Effective protection of the environment

2.I Avoiding pollution

$2 \cdot 2$ Protecting and enhancing biodiversity

2.3 Transport planning

3.0 Prudent use of natural resources

3.I Improved energy efficiency

3.2 Efficient use of resources

Social sustainability

4.0 Social progress which recognises the needs of everyone

4.I Respect for staff

4.2 Working with local communities and road users

4.3 Partnership working
Improved productivity

Consistent profit growth

Employee satisfaction

Supplier satisfaction

Client satisfaction

Minimising defects

Shorter and more predictable completion time

Lower cost projects with increased cost predictability

Delivering services that provide best value to clients and focus on developing client business

Company reporting

Benchmarking performance

Minimising polluting emissions

Preventing nuisance from noise and dust by good site and depot management

Waste minimisation and elimination

Preventing pollution incidents and breaches of environmental regulations

Habitat creation and environmental improvement

Protection of sensitive ecosystems through good construction practices and supervision

Green transport plan for sites and business activities

Energy efficient depots and sites

Reduced energy consumption in business activities

Design for whole-life costs

Use of local supplies and materials with low embodied energy

Lean design and construction avoiding waste

Use of recycled/sustainability sourced products

Water conservation

Waste minimisation and management

Provision of effective training and appraisals

Equitable terms and conditions

Provision of equal opportunities

Health, safety and conducive working environment

Maintaining morale and employee satisfaction

Participation in decision-making

Minimising local nuisance and disruption

Minimising traffic disruptions and delays

Building effective channels of communication

Contributing to the local economy through local employment and procurement

Delivering services that enhance the local environment

Building long-term relationships with clients

Building long-term relationships with local suppliers

Corporate citizenship

Delivering services that provide best value to clients and focus on developing client business

Contributing to sustainable development globally

Table 2. Key sustainability issues

Q3: Is the full spectrum of issues usually implied by the term 'sustainability' being addressed within the case organisations?

3.6.3. Enablers and barriers to SSCM. SSCM research in other industries suggests potential benefits and pitfalls. ${ }^{13,14}$ As the sustainability performance of supply chains becomes more important to companies, various techniques are being introduced for better understanding of the issues, assessing the risks, monitoring suppliers' performance and raising standards along the chain. ${ }^{14,62}$ Research indicates that most of these tools are still at an embryonic stage of development and there is still some degree of uncertainty regarding which are the most practical, credible, efficient and cost effective. In addition, the choice of tools for individual firms depends on organisation culture, market position and sustainability issues most exposed to. ${ }^{62}$ 
Q4: What are the drivers, benefits, barriers, tools and techniques used within case study organisations to integrate sustainability issues in their supply chain? Do the sustainability issues exposed to culture and market position of individual organisations impact on the choice of tools and techniques?

3.6.4. Conditions for successful SSCM. The previous discussion on inter-firm relationships (Fig. 3) has been based on literature relating to successful integration of environmental issues within SCM. Innovative approaches to reducing packaging in the healthcare and retail sectors provide good examples of collaboration based on trust and equity. Examples of collaboration based on dominance and power regimes include how Toyota successfully achieves its 'lean' and environmental management objectives and how BCQQ successfully integrates environment and wider sustainability objectives throughout their supply chains. This evidence suggests that the diffusion of environmental objectives differs between industries and supply chains with different structural formations and the effectiveness of green purchasing policies varies between contexts. ${ }^{58}$

It is imperative that certain conditions are met for effective SSCM. A review of related literature ${ }^{13,14,63}$ suggests that conditions such as top-level leadership, cross-functional teams and effective communication (see Table 3 for full lists) are required for successful implementation of SSCM. These conditions were examined and validated within the case study organisations and the outcomes are summarised in Table 3.

\begin{tabular}{|c|c|c|}
\hline No. & SSCM conditions & Assessment \\
\hline 1 & Top-level leadership & $\begin{array}{l}\text { High: it is common practice that senior management meet regularly to } \\
\text { discuss progress and set targets. }\end{array}$ \\
\hline 2 & Cross-functional integration & $\begin{array}{l}\text { Moderate: some functions are more involved than the others. } \\
\text { Although there is evidence of horizontal structure, the historical } \\
\text { dichotomy between departments and functions still persists. }\end{array}$ \\
\hline 3 & Effective communication & $\begin{array}{l}\text { High: there are well-established modes of both internal and external } \\
\text { communications, for example periodic meetings, annual } \\
\text { communication day to engage all stakeholders, and information on } \\
\text { the intranet, extranet and internet. }\end{array}$ \\
\hline 4 & Multiple information channels & $\begin{array}{l}\text { High: there is substantial evidence, for example mission statements, } \\
\text { codes of conduct, meetings, questionnaires, contract conditions, } \\
\text { supplier newsletters, and periodic performance reviews. }\end{array}$ \\
\hline 5 & $\begin{array}{l}\text { Effective processes for targeting, selecting, } \\
\text { working with and evaluating suppliers }\end{array}$ & $\begin{array}{l}\text { High: evidence suggests a host of advanced and innovative tools and } \\
\text { strategies. }\end{array}$ \\
\hline 6 & $\begin{array}{l}\text { Must target first-tier suppliers, contractors/ } \\
\text { subcontractors }\end{array}$ & $\begin{array}{l}\text { Moderate: not in all cases. There is a reluctance to reduce the number } \\
\text { of suppliers and subcontractors. }\end{array}$ \\
\hline 7 & $\begin{array}{l}\text { Incorporate sustainability issues as part of supplier } \\
\text { solicitation, selection and monitoring to ensure } \\
\text { that only sustainability-aware suppliers } \\
\text { approach them for business }\end{array}$ & $\begin{array}{l}\text { Moderate: the process is highly geared towards the environmental } \\
\text { aspect of sustainability and less on other aspects. }\end{array}$ \\
\hline 8 & Integration into existing SCM processes & $\begin{array}{l}\text { High: but the focus is more on environmental aspects and less on } \\
\text { other aspects of sustainability. }\end{array}$ \\
\hline 9 & Ensure continuous improvement & $\begin{array}{l}\text { High: the relationship is based on continuous improvement; as a result } \\
\text { there is a business improvement department with senior } \\
\text { management involvement. Employees are encouraged and } \\
\text { rewarded for innovative ideas. }\end{array}$ \\
\hline 10 & $\begin{array}{l}\text { Willingness to end relationships which fail } \\
\text { repeatedly to meet environmental expectations }\end{array}$ & $\begin{array}{l}\text { Moderate: not necessarily based on environmental issues alone but as } \\
\text { well as (if not more on) price commitment. }\end{array}$ \\
\hline II & Allow for collaboration and joint problem-solving & $\begin{array}{l}\text { High: various innovation in material and construction processes are } \\
\text { evidence of collaborations among the parties. }\end{array}$ \\
\hline 12 & Process must be rewarding for all parties & $\begin{array}{l}\text { Low: the process is mainly geared towards reducing cost for and } \\
\text { meeting the client's public services agreement (PSA) targets. }\end{array}$ \\
\hline 13 & Partnership culture & $\begin{array}{l}\text { High: there is very strong evidence of partnership culture and most of } \\
\text { the parties interviewed are regarded as the pioneers of strategic } \\
\text { partnering in the sector. Contracts are awarded through strategic } \\
\text { partnering on a 5-year term maintenance contract (local } \\
\text { authorities) or management agent contractor (MAC in the } \\
\text { Highways Agency). With these arrangements, contractors, } \\
\text { suppliers and subcontractors work together to achieve clients } \\
\text { objectives. }\end{array}$ \\
\hline 14 & $\begin{array}{l}\text { Transparency and trust among all the parties } \\
\text { involved }\end{array}$ & $\begin{array}{l}\text { Moderate: evidence from a few subcontractors and suppliers suggest } \\
\text { an arm's-length relationship with their clients and/or contractors. } \\
\text { In general, there seems to be an element of trust and honesty. } \\
\text { However, this assertion is purely based on the fact that most of the } \\
\text { parties interviewed have been working together for over } 10 \text { years } \\
\text { and one of the contractors described their relationship with clients } \\
\text { as 'closely tight'. }\end{array}$ \\
\hline 15 & Shared vision and strategy & $\begin{array}{l}\text { Moderate: although a shared vision and strategy exists, the cultural } \\
\text { barriers and the historic division of functions and departments } \\
\text { make this difficult to maintain and execute. }\end{array}$ \\
\hline
\end{tabular}


Q5: To what extent do these conditions exist and which type of inter-firm relationship exists in the case study organisations that facilitate the diffusion of sustainability issues within the supply chain?

\section{RESEARCH FINDINGS AND DISCUSSION}

Based on in-depth semi-structured interviews, the answers to the above five research questions can be summarised as follows.

\section{I. Understanding of the concept}

The initial stage of the study explored the interviewees' understanding of SCM, sustainable construction and SSCM. The clients' descriptions of SCM reflected the public sector's perspective while contractors' descriptions tended to follow the construction industry's perspective, as shown in Fig. 2. There is a general consensus among all parties that sustainability is a complex and cross-cutting concept. It was recognised, however, that sustainability comprises three components: environmental, social and economic issues. With the exception of the subcontractors, one supplier and one contractor, all the interviewees confirmed that their organisations have developed sustainability strategies and produced documentation to prove this. There is evidence that all have either environmental management system (EMS) certification to ISO 14001 or in-house EMS systems. The term SSCM is generally unknown but there is a very high level of awareness of green procurement, green purchasing and environmental supply chain management. This is understandable, as these are common terms within the clients' organisations (public sector) and the reflection of the scope of sustainability issues addressed with the SCM.

\subsection{Sustainability issues addressed}

There appears to be a lack of integration of the wide spectrum of sustainability issues within SCM and a focus on environmental issues, possibly due to the clients' green procurement policy (the 'Greening Government' programme focuses on the incorporation of environmental concerns into public procurement) and the high exposure of the sector to environmental legislations (as many similarities exist between the waste management and road maintenance sectors). The analysis of the sustainability issues addressed within the supply chain mainly focused on the environmental aspect of sustainability that can yield economic rewards. Examples of these were waste management to reduce landfill tax, recycling initiatives, material innovation, pollution avoidance, reduction of generic construction material usage (water, energy), transport policy (to minimise disruption to road users during road works) and so on. The only social issue being addressed appeared to focus on health and safety, possibly due to poor health and safety records in the industry.

\subsection{Functions/departments involved in integrating sustainability issues in the SCM}

The research results indicate that some of these departments/ functions are more involved than the others, as shown in Fig. 5. The most involved department/function is the procurement/ purchasing department while the least involved is the human resources department. This finding is consistent with the common perception within the construction industry that

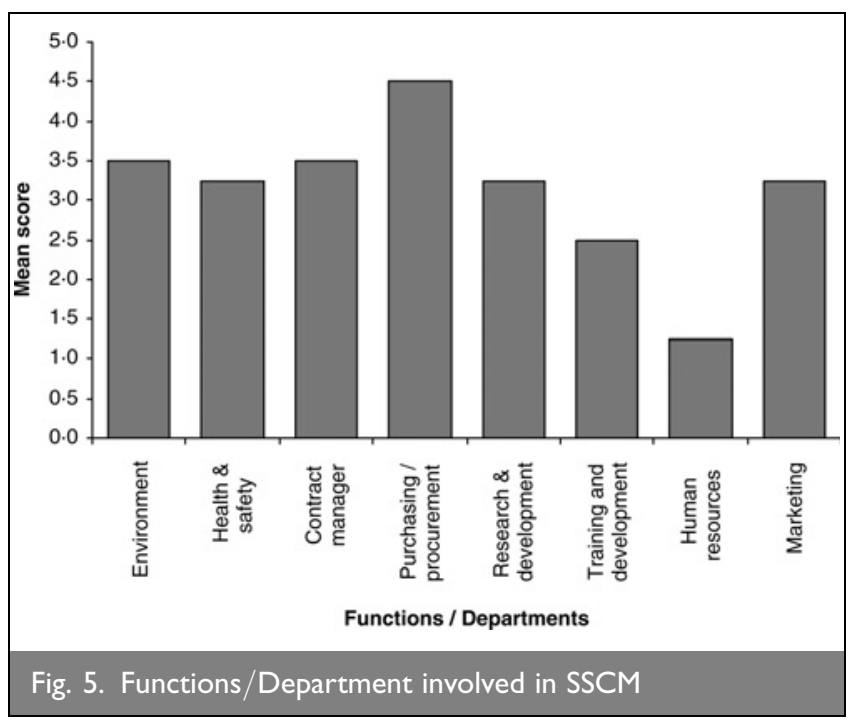

environmental concerns are more tangible than the social aspect of sustainability.

\subsection{Drivers for integrating sustainability issues in SCM}

The research has also demonstrated the power of clients to initiate change. Several of the contractors, subcontractors and suppliers suggested that clients' requests for better environmental and health and safety performance have yielded major influence in getting support at board level, the main catalyst for achieving environmental management accreditation to ISO 14001. Some, with the exception of the subcontractors, indicate that their organisations also have or are in the process of working towards third-party accreditations such as Investors in People, Quality Management ISO 9000: 2000, and health and safety (RoSPA and/or OHSAS). The research suggests that the main drivers are: achieving best value for the client; meeting clients' targets; minimising risk; compliance with environmental legislation and contractual requirements; maximising added value; reducing total cost across the entire trading process; and gaining competitive advantage. These drivers can be broadly grouped into customer focus, cost leverage and environmental innovation.

\subsection{Benefits of integrating sustainability issues in SCM}

The supply chain provides the focus for any organisation seeking to improve the social, environmental and economic performance of its operations. Substantial business benefits can be achieved through a combination of leadership commitment, practical initiatives and improved systems and processes. Most of the respondents indicated a positive impact on the economic bottom line and cited several business benefits such as improved image, legislative compliance and cost savings, as shown in Fig. 4. This suggests that business value can result from the successful integration of environmental/sustainability issues throughout the supply chain.

\subsection{Barriers to integrating sustainability issues in SCM}

The respondents conveyed a number of barriers to overcome when collaborating on environmental/sustainability initiatives. The findings pointed to some intriguing problems. The cited major barriers included: the difficulty of achieving behavioural 
Pre-qualification assessment

Third-party certification

Pre-qualification database

Continuous improvement agreement

Behavioural code of practice

Procurement and contract guidelines

Strategic alliance and partnering

Validation of performance

Training and communication

Collaboration with supply chain

Operational integrity

Purchasing specifications
This includes qualitative (essay format, e.g. quality submission) and quantitative (rating of statements, e.g. capability assessment toolkit) methods. The quality submission is common within the local authority contracts, which demand written statements from contractors on a set of issues such as design, recycling initiatives, innovation in material use and other environmental issues. Very recently, the Highways Agency introduced CAT, a self-assessment tool covering such issues as internal resources, partnering, processes, people, strategy and planning, direction and leadership.

This includes ISO I400 I Environmental standard. Many clients insist that their contractors and suppliers meet this standard.

Details include contractors, suppliers and subcontractors that meet legislative requirement, high environmental management standard with proven records of technical ability and innovation. This is undertaken through questionnaires and interviews on environmental policy, awareness and achievements, and working conditions.

Procurement contracts for supply chain parties to work with clients to continuously improve the environmental performance and achieving the governmental public sector agreement (PSA) are required.

Where appropriate, projects are registered on the considerate contractor scheme (CCS). The CCS is a voluntary initiative for better site management to reduce site noise and nuisance and waste and to improve working relationships between contractors and subcontractors.

Handbooks containing procurement procedures, environmental requirements, environmental manual containing a list of hazardous substances to be avoided, vehicle procurement specifications and so on.

Contracts are awarded to contractors on a 5-year basis through strategic alliance. Partnering between contractors and first-tier subcontractors and suppliers, where appropriate, is common.

This is a crucial part of the management process. Examples of tools used for validations are reviewing questionnaires and documentation from contractors, subcontractors and suppliers, site visits, third-party audits, and measurement of contract performance using jointly agreed indicators.

Third party and in-house training on such issues as environmental and health and safety issues. Communication materials such as Toolbox talks, workshops, brochures, information on the internet and intranets, and newsletters are commonly used.

Collaborating on R\&D, development of environmentally efficient products, waste management systems, to meet environmental targets and so on. There are hosts of examples of innovation through collaboration in the area of waste management, resources use and material.

Contractors are required to work toward ISO I400I certification for their depots. Individual businesses within the group set up their own management systems to comply with the parent company's environmental requirements. Use of environmental coordinators at various levels working closely with procurement and marketing departments is required.

For product and services this is a useful tool for influencing the supply chains. Examples of purchasing specifications involve restriction on certain environmental damaging substances, amount of recycling material use, whole-life costing outcome and so on.

Table 4. Inventory of tools and techniques within case study organisations

and cultural change; procurement restriction; cost issues; commercial risks; clients' unwillingness to pay a premium for sustainable construction innovation; and rigid specifications. These and other challenges are outlined below.

(a) Restriction of World Trade Organisation (WTO) and European Union (EU) legislation on procurement: the UK public sector's SSCM is restricted by the global and continental trade rules such as the government procurement agreement, and the EU Treaty, which both mandate 'open tendering' and nondiscrimination procurement practices for the member countries.

(b) Laxity of procurement policy: the UK government's procurement policy is mainly based on the concept of "value for money'. Due to the devolved nature of procurement responsibilities, however, the scope of its practical application mainly depends on the different levels of government and specific department. This appears to be a major barrier to SSCM. There is still no 'level playing field' as procurement practices have largely been focused on price whereas the commitment to sustainability issues has been an act of faith rather than a contractual deliverable.

(c) Symbolic quality submission: pre-selection systems tend to accept 'just enough' as the pass mark and then allow the next phase of the tender process to be awarded primarily on a cost basis which does not reward those companies 'making a real difference'.

(d) Low-risk culture: there is a general perception that clients are unwilling to take or share risks and opt for tried and tested materials and construction processes.

(e) Cost of innovation and commercial risk: clients are sometimes unwilling to share the cost or pay a premium for sustainable construction innovation. Because of commercial risk, and a long history of conservative and adversarial relationship, suppliers do not always share certain 
commercial information and hence there are practical limits to transparency and an open-book approach.

\subsection{Tools and strategy used for implementing SSCM}

The research findings suggest the existence of wide-ranging, advanced and innovative SSCM tools and techniques in operation. These tools and techniques, however, mainly focus on environmental aspects and not on other aspects of sustainability issues. The research demonstrated a high culture of health and safety and environmental consciousness within the case study organisations, possibly due to the sector's high exposure to environmental, health and safety issues and the client's green procurement strategy. The high exposure and client's market position appear to have influenced the choice of tools and strategies as more importance is placed on achieving third-party certification. The inventory of tools and techniques used within the sector is presented in Table 4.

\subsection{Assessment of the conditions for SSCM and type of inter-firm relationships}

This assessment was based on the discussions and observations during the interviews and on the review of literature and documents from the case study organisations. The conditions for SSCM are assessed on a three-point scale; namely high, medium and low. The inter-firm relationship observed in the supply chain network has the characteristics of structural dominance and power regime (school of thought B in Fig. 3). This structural dominance exists in the client-contractor relationships and the contractor's network of subcontractors and suppliers' relationships. This situation is referred to as extended buyer (client) dominance. ${ }^{15}$ Such an environment is argued to be one of the most conducive environments for successful implementation of SCM in the construction industry. ${ }^{15,64}$ In the road maintenance sector, there are very few major contractors and the only sources of revenue are government agencies (such as local authorities and the Highways Agency). The client's main priority is to maintain the road network within budget with minimal disruptions to road users and low environmental impacts.

The large volume and regularity of workload, extensive knowledge of the road maintenance process and the high revenue dependence of the main contractors and their supplier chain networks have helped clients to achieve their business objective, that is obtaining 'value for money'. The Highways Agency, through extended structural dominance, is able to control its supply chain by adopting a long-term strategic partnering arrangement with the contractor. The main contractor selection criteria, apart from cost, are evidence of: environmental policy; innovation in material and construction process; supply chain network of subcontractors and suppliers; and health and safety performance of the main contractors. The contractor is also able to leverage power on its selected/preferred supply chain network of subcontractors and suppliers through regularity of workload, high purchasing power and extensive knowledge of the maintenance process. This approach is highly proactive and enables the clients to directly manage the upstream and indirectly manage the downstream supply chains and facilitate the diffusion of environmental/sustainability issues.

\section{CONCLUSIONS}

The terms SCM and SSCM are evolving concepts and SSCM can be defined as: identification of problematic economic, social and environmental issues throughout the supply chain; assessment of their potential impact and risks; and development of measures to enhance impact and mitigate risk. ${ }^{13}$ Through extensive literature review and detailed interviews, this research has established the conditions and strategies for achieving SSCM in the construction industry. The research also investigated the meaning, barriers and enablers, issues, tools and techniques for achieving successful SCM and SSCM, based on the perspectives of senior managers from exemplar organisations with a proven track record in implementing sustainability issues and good supply chain management.

Within the investigated sector, the study revealed a general understanding of sustainability and supply chain concepts. However, the term SSCM is relatively unknown or considered from the perspective of green procurement/purchasing. This is consistent with the SSCM practice found within the organisations studied, the main reasons being clients' green procurement strategies and the potentially high environmental impact by this sector. The study observed a high culture of health and safety and environmental consciousness within the case study organisations, due to the sector's high exposure to environmental, health and safety issues. The high exposure and clients' market position appeared to have influenced the choice of tools and strategies, as more importance is placed on achieving third-party certification and meeting clients' targets. The research findings suggest the existence of a spectrum of advanced and innovative SSCM tools and techniques in operation such as strategic alliance, pre-qualification assessment, third parities certification, validation of performance, continuous improvement agreement and so on, as collated in Table 4.

This research has examined the debate on the uncertainty regarding the circumstances amenable to achieving SCM in the construction industry. In this context, two schools of thought for achieving SCM were found in the literature, as depicted in Fig. 3. Due to the nature and complexity of many construction processes, SCM relationships within the industry are, more often than not, based on dominance and power regime as confirmed in the study. The inter-firm relationships observed in the supply chain network possess the characteristics of extended structural dominance and power regime and provide the environment for the diffusion of sustainability issues. Most of the respondents indicated a positive impact on the bottom line and cited several business benefits, as shown in Fig. 4. This indicates that a well-crafted and successful integration of environmental/sustainability issues throughout the supply chain can create business value. SSCM therefore provides a rare opportunity to create value; however, the construction industry needs to fully embrace SSCM if it is to achieve sustainable construction.

\section{REFERENCES}

1. Department for Environment, Transport and the Regions. A Better Quality of Life: A Strategy for more Sustainable Construction. DETR, London, 2000.

2. Garson P. Review of Civil Procurement in Central Government. Office of Government Commerce, London, 1999. 
3. Her Majesty's Treasury. Appraisal and Evaluation in Central Government: The Green Book. The Stationery Office, London, 2003.

4. Her Majesty's Treasury. Procurement Guidance Note No. 7 - Whole Life Costing. Stationery Office, London, 2000.

5. LATHAM M. Constructing the Team. Her Majesty's Stationery Office, London, 1994.

6. Egan J. Rethinking Construction, Construction Task Force Report. Her Majesty's Stationery Office, London, 1998.

7. Adetunji I., Price A. D. F., Fleming P. and Kemp P. Trends in the conceptualisation of corporate sustainability. Proceedings of the Joint International Symposium of CIB Working Commissions W55, W65 and W107, Singapore, 2003.

8. Government Construction Clients' Panel. Achieving Sustainability in Construction Procurement. GCCP, London, 2000.

9. Adetunji I., Price A. D. F., Fleming P. and Kemp P. Sustainability and the UK construction industry: a review. Proceedings of the Institution of Civil Engineers Engineering Sustainability, 2003, 156, No. 4, 185-199.

10. Elkington J. Cannibals with Forks: The Triple Bottom Line of $21^{\text {st }}$ Century Business. Castone Publishing, London, 2002.

11. SIGMA. SIGMA Project, 2000. See www.projectsigma.com, accessed 25/01/2008.

12. Nattrass B. and Altomare M. The Natural Step for Business: Wealth, Ecology and the Evolutionary Corporation, 2nd edn. New Society Publishers, Canada, 2001.

13. DrabÆK I. and Brinch-Pedersen M. Sustainable development as a business principle in the supply chain: no writing on the wall. Nordic Partnership discussion paper, August 2003, available at www.infoagro.net/shared/docs/ a6/SustDevBusiness.pdf

14. Carter M., Kielkiewicz-Young A., Young A. and Hughes A. Supply chain strategy and evaluation. The Centre for Sustainable Design, SIGMA project, 2001.

15. IRELAND P. Managing appropriately in construction power regimes: understanding the impact of regularity in the project environment. Supply Chain Management: An International Journal, 2004, 9, No. 5, 372-382.

16. CoX A. and IRELAND P. Managing construction supply chains: a common sense approach. Engineering, Construction and Architectural Management, 2002, 9, No. 5/6, 409-418.

17. Yin K. R. Case Study Research: Design Methods, Applied Social Research Methods Series, Vol. 5. Sage Publication, London, 1994.

18. Brundtland G. H. Our Common Future. Report of the World Commission on Environment and Development, New York, 1987.

19. Houlihan J. B. International supply chain management. International Journal of Physical Distribution and Materials Management, 1985, 15, No. 1, 51-56.

20. BiemAnS W. and BRAND M. Reverse marketing: a synergy of purchasing and relationship marketing. International Journal of Purchasing and Materials Management, 1995, 31, Summer, 29-37.

21. CoX A. Business Success. Earlsgate Press, Boston, UK, 1997.

22. Bechtel C. and Jayaram J. Supply chain management: a strategic perspective. International Journal of Logistics Management, 1997, 8, No. 1, 15-34.

23. ANDERSON D. L. and LEE H. Synchronized supply chains: the new frontier. Achieving Supply Chain Excellence through
Technology. Montgomery Research, San Francisco, CA, 1999, pp. 12-21.

24. MAinheim M. L. Integrating people and technology for supply chain advantage. Achieving Supply Chain Excellence through Technology. Montgomery Research, San Francisco, 1999, 304-313.

25. Dewhurst F., Spring M. and Arkle N. Environmental change and supply chain management: A multi-case study exploration of the impact of Y2000. Supply Chain Management: An International Journal, 2000, 5, №. 5, 245-260.

26. VOLLMANN T. and CORDON C. Building a smarter demand chain, mastering information management, part 4. Financial Times, February 1999.

27. New S. Supply chain integration: hype or reality? Logistics Focus, 1994, 2, No. 5.

28. HARLAND C. M. Supply chain management: relationships, chains and networks. British Journal of Management, Special Issue, 1996, 7, S63-S80.

29. Ross D. F. Competing through Supply Chain Management: Creating Marketing-winning Strategies through Supply Chain Partnerships. Chapman \& Hall, New York, 1998.

30. Dainty A. R. J., Briscoe H. G. and Millet S. J. New perspectives on construction supply chain integration. Supply Chain Management: An International Journal, 2001, 6, No. 4, 163-173.

31. O’BRIEN W. J. and Fisher M. A. Construction supply chain management: a research framework. Proceedings of Civil Comp 93: Information Technology for Civil and Structural Engineers (Topping B. H. V. and KahN A. I. (eds)), 1993, 61-64.

32. HAYWARD D. Setting store. New Civil Engineer, Movement for Innovation Supplement, 1999, November, 24-25.

33. Mylius A. Keyhole surgery. New Civil Engineer, Movement for Innovation Supplement, November, 1999, 21-22.

34. Whitelaw J. Breaking the mould. New Civil Engineer, Movement for Innovation Supplement, November, 1999, 2-8.

35. Sabath R. and Fontanella J. The unfulfilled promise of supply chain collaboration. Supply Chain Management Review, 2002, July/August, 24-29.

36. Love P. E. D. Construction supply chains. European Journal of Purchasing and Supply Management, 2000, 6, No. 3-4, 145-147.

37. Pearson A. Chain reaction. Building, 12 March 1999, pp. 54-55.

38. Gattorna J. J., Chorn N. C. and Day R. Pathways to customer: reducing complexity in the logistics pipeline. International Journal of Physical Distribution and Materials Management, 1992, 15, No. 1, 51-56.

39. IRELAND R. and BRUCE R. CPFR only the beginning of collaboration. Supply Chain Management Review, 2002, September/October, 80-88.

40. McIvor R., Humphreys P. and McAleer E. Implications of partnership sourcing on buyer-supplier relations. Journal of General Management, 1997, 23, No. 1, 30-35.

41. New S. and RAmSEY J. A critical appraisal of aspects of the lean chain approach. European Journal of Purchasing and Supply Management, 1997, 3, No. 2, 93-102.

42. WATSON K. Is partnering starting to mean all things to all people. Contract Journal, 1999, 387, No. 6212, 14-16.

43. Akintoye A., McIntosh G. and Fitzgerald E. A survey of supply chain collaboration and management in the UK 
construction industry. European Journal of Purchasing and Supply Chain Management, 2000, 6, No. 3-4, 159-168.

44. Humphreys P., Matthews J. and Kumaraswamy M. Preconstruction project partnering: from adversarial to collaborative relationships. Supply Chain Management: An International Journal, 2003, 8, No. 2, 166-178.

45. LEE H. L. and BILLINGTON C. Managing supply chain inventory: pitfalls and opportunities. Sloan Management Review, 1992, 33, No. 3, 65-73.

46. Spekman R. E., Kamauff J. W. Jr. and Myhr N. An empirical investigation into supply chain management: a perspective on partnerships. Supply Chain Management: An International Journal, 1998, 3, No. 2, 53-67.

47. Cox A. The art of the possible: relationship management in power regimes and supply chain. Supply Chain Management: An International Journal, 2004, 9, No. 5, 346-356.

48. Cox A. Power, value and supply chain management. Supply Chain Management: An International Journal, 1999, 3, No. 4, 167-175.

49. Shimizu I. The Dark Side of Japanese Business. M.E. Sharpe, Armonk, New York, NY, 1996.

50. Simpson D. F. and Power D. J. Use the supply relationship to develop lean and green suppliers. Supply Chain Management: An International Journal, 2005, 10, No. 1, 60-68.

51. MoHR J. and Nevin J. R. Communication strategies in marketing channels: a theoretical perspective. Journal of Marketing, 1990, 54, October, 36-51.

52. Wagner B. A., Macbeth D. K. and Boddy D. Improving supply chain relations: an empirical case study. Supply Chain management: An International Journal, 2002, 7, No. 4, 253-264.

53. LOVE P. E. D., IRANi Z. and Edwards D. J. A seamless supply chain management model for construction. Supply
Chain Management: An International Journal, 2004, 9, No. 1, 43-56.

54. VRIJHoef L. and Koskela L. The four roles of supply chain management in construction. European Journal of Purchasing and Supply Chain Management, 2000, 6, No. 3-4, 169-178.

55. OFORI G. Greening the construction supply chain in Singapore. European Journal of Purchasing and Supply Management, 2000, 6, No. 3-4, 195-206.

56. KeEgan K. Managing the portfolio of supply chain competencies. Supply Chain Management Review, 1999, 3, No. 2, 44-51.

57. Westbrook B. Synchronize for success. Supply Chain Management Review, 1999, 3, No. 60-66.

58. Green K., Morton B. and New S. Green purchasing and supply policies: do they improve company's environmental performance? Supply Chain Management: An International Journal, 1998, 3, No. 2, 89-95.

59. WS AtKins Consultants. C563: Sustainable Construction: Company Indicators. CIRIA, London, 2001.

60. Addis B. and Talbot R. C571: Sustainable Construction Procurement: A Guide to Delivering Environmentally Responsible Projects. CIRIA, London, 2001.

61. Leiper Q., Fagan N., Engstrom S. and Fenn G. A strategy for sustainability. Proceedings of the Institution of Civil Engineers, Engineering Sustainability, 2003, 156, No. 1, 59-66.

62. RoBerTs S. Supply Chains as a Lever for Sustainability? Progress, Prospects and Pitfalls. International Institute for Environment and Development, London, 2001.

63. Lippmann S. Supply chain environmental management: elements for success. Environmental Management, 6, No. 2, 175-182.

64. Cox A. Business Relationships for Competitive Advantage. Palgrave Macmillan, Basingstoke, 2004.

\section{What do you think?}

To comment on this paper, please email up to 500 words to the editor at journals@ice.org.uk

Proceedings journals rely entirely on contributions sent in by civil engineers and related professionals, academics and students. Papers should be 2000-5000 words long, with adequate illustrations and references. Please visit www.thomastelford.com/journals for author guidelines and further details. 